peripheral lymphocyte phenotyping using 8-colour flow cytometry, with specific focus on helper T cell subsets, between 26 patients with PSA and healthy donors. In addition, the therapeutic response of 26 patients in whom the optimal bDMARDs was strategically chosen based on the results of peripheral lymphocyte analysis was evaluated at 6 months of treatment intervention in comparison with 38 patients in whom the standard biological product was used based on the 2011 and 2015 EULAR recommendations. Thus, the possibility of the optimisation of drug selection for bDMARDs therapy based on peripheral blood lymphocyte phenotyping was investigated.

Results: The 26 patients with PsA in the strategic treatment group were classified into the following 4 types based on the peripheral blood analysis: a $\mathrm{CXCR}^{+}{ }^{+} \mathrm{CR} 6{ }^{-}{ }^{-} \mathrm{CD} 38^{+} \mathrm{HLA}-\mathrm{DR}^{+}$activated Th1 cell-predominant type, $\mathrm{CXCR}^{-} \mathrm{CCR}^{+}{ }^{+} \mathrm{CD}^{2} 8^{+} \mathrm{HLA}^{-\mathrm{DR}^{+}}$activated Th17 cell-predominant type, Th1/ Th17-high type, and Th1/Th17-low type. Accordingly, ustekinumab was administered to the activated Th1 cell-predominant patients, secukinumab to the activated Th17 cell-predominant patients, secukinumab or TNF inhibitor to the Th1/Th17high patients, and TNF inhibitor to the Th1/Th17-low patients. At 6 months of strategic treatment, there was a significant decrease in SDAI (from 16.2 to 3.52), DAS28 (ESR) (from 4.13 to 2.27), and PASI (from 8.36 to 2.40). There were no statistically significant differences in background factors at baseline between these 2 groups. Moreover, the proportion of patients with the combined use of MTX was significantly lower in the strategic bDMARDs treatment group. There were significant decreases in TJC, SJC, PGA, CRP, ESR, DAS28 (ESR), SDAI, and PASI in both groups at 6 months of therapy. There were no significant differences in the amounts of these decreases between the two groups. However, at 6 months of therapy, the rate of low disease activity achievement according to SDAI, DAS28 (ESR), and ACR20 response rate was significantly higher in the strategic bDMARDs treatment group.

Conclusions: Strategic treatment in which different bDMARDs were selected according to phenotypic differences in helper $\mathrm{T}$ cells showed significantly higher efficacy than standard bDMARD therapy. The results of this study provide an important guide to the implementation of more effective therapeutic intervention.

Disclosure of Interest: None declared

DOI: 10.1136/annrheumdis-2018-eular.3829

FRIDAY, 15 JUNE 2018

The art of diagnosis of axial SpA

\section{OP0322 ARE WE TREATING WITH BIOLOGICAL THERAPIES WOMEN PATIENTS WITH REAL NON-RADIOGRAPHIC AXIAL SPONDYLOARTHRITIS?}

$\underline{\text { R.E. Nieto }}^{1}$, C. Plasencia ${ }^{2}$, D. Peiteado ${ }^{2}$, A. Villalba $^{2}$, A. Balsa ${ }^{2}$, V. NavarroCompán ${ }^{2}{ }^{1}$ Hospital Provincial de Rosario, Rosario, Argentina; ${ }^{2}$ University Hospital La Paz, IdiPaz, Madrid, Spain

Background: As a result of the development of the ASAS criteria for axial spondyloarthritis (axSpA), a new entity (non-radiographic axSpA -nr-axSpA) was created. In some countries major concerns have been raised with regard to this entity because this could imply administrating TNF inhibitors (TNFi) to non-SpA patients. Especially the possibility of treating women with fibromyalgia has been mentioned.

Objectives: To evaluate if the gender distribution and the pattern of patients have changed in clinical practice since TNFi were approved for nr-axSpA.

Methods: Dataset from a prospective cohort including all patients with axSpA treated with biological therapy (BT) since 2000 till August-2017 in a tertiary hospital was analysed. Patients' and disease' characteristics and disease activity parameters were collected at baseline. Based on the starting date for the first BT, patients were classified in two groups: i) before 2013 and ii) during or after 2013, since the nr-axSpA approval-date for TNFi in the country was July 2012. Gender distribution and other characteristics were compared between both groups using Chi-square and Student-t tests.

Results: In total, 385 axSpA patients initiated BT. Out of these, 266 initiated BT in period i) and 119 in period ii). The characteristics of patients in both groups are depicted in table 1. Importantly, no differences between period i) and ii) were observed regarding gender distribution ( $38 \%$ and $39 \%$ of women; $p=0.8$, respectively). Additionally, during period ii), the percentage of patients with $\mathrm{nr}-\mathrm{axSpA}$ was similar for both genders and out of all patients with $\mathrm{nr}-\mathrm{axSpA}$, the majority $(60 \%)$ were men. Overall, disease duration was shorter in period ii for both genders. Women in period ii) had significantly higher ASDAS, BASMI and CRP than women in period i) and higher ASDAS, BASDAI and BASFI than men in period ii).
Abstract OP0322 - Table 1 Patients characteristics stratified for starting first TNFi period and gender

\begin{tabular}{|c|c|c|c|c|c|c|}
\hline & \multicolumn{3}{|c|}{$2000-2012$} & \multicolumn{3}{|c|}{ 2013-2017 } \\
\hline & $\begin{array}{c}\text { Total } \\
n=266\end{array}$ & $\begin{array}{l}\text { Males } \\
n=164\end{array}$ & $\begin{array}{c}\text { Females } \\
n=102\end{array}$ & $\begin{array}{c}\text { Total } \\
n=119\end{array}$ & $\begin{array}{c}\text { Males } \\
n=72\end{array}$ & $\begin{array}{c}\text { Females } \\
\mathrm{n}=47\end{array}$ \\
\hline Age, yrs mean (SD) & $43.7(11.9)$ & $43.7(11.4)$ & $43.6(12.8)$ & $45.1(14.1)$ & $43.9(13.8)$ & $47.0(14.5)$ \\
\hline Smokers $\%$ & 44 & 47 & 39 & 49 & 47 & 51 \\
\hline $\begin{array}{l}\text { Disease duration, } \\
\text { months median (IQR) }\end{array}$ & $61.0(125.0)$ & $63.5(136.5)$ & $55.5(118.0)$ & $51.0(119.0)$ & $62.5(139.5)$ & $49.0(106.0)$ \\
\hline HLA-B27\% & 60 & 65 & 54 & 57 & 57 & 57 \\
\hline BASDAI median (IOR) & $6.0(2.3)$ & $5.7(2.5)$ & $6.9(2.4)$ & $6.0(2.4)$ & $5.8(2.2)^{+}$ & $6.5(2.6)^{+}$ \\
\hline ASDAS mean (SD) & $3.3(0.9)$ & $3.3(1.0)$ & $3.3(0.9)$ & $3.4(1.0)$ & $3.2(1.0)^{+}$ & $3.6(3.4)^{+}$ \\
\hline BASFI median (IQR) & $5.0(3.8)$ & $4.9(3.7)$ & $5.3(3.0)$ & $4.7(3.8)$ & $4.3(4.1)^{+}$ & $5.7(2.9)^{+}$ \\
\hline BASMI median (IIQR) & $2.1(2.2)$ & $2.4(2.4)$ & $2.0(1.4)^{*}$ & $2.4(2.0)$ & $2.2(2.2)$ & $2.7(1.7)^{*}$ \\
\hline CRP median (IQR) & $4.1(10.1)$ & $4.3(6.8)$ & $3.2(7.4)^{*}$ & $7.5(16.7)$ & $6.8(17.0)$ & $10.2(21.9)^{*}$ \\
\hline PtGA median (IQR) & $69(30.0)$ & $67(30.0)$ & $70(30.0)$ & $70(30.0)$ & $70(30.0)$ & $70(30.0)$ \\
\hline PGA median (IQR) & $45(40.0)$ & $40(40.0)$ & $50(40.0)$ & $45(30.0)$ & $40(30.0)$ & $45(30.0)$ \\
\hline $\begin{array}{l}\text { Peripheral } \\
\text { involvement, \% }\end{array}$ & 43 & 35 & 57 & 48 & 46 & 51 \\
\hline DMARDs, $\%$ & 49 & 47 & 51 & 51 & 46 & 60 \\
\hline $\mathrm{Nr}$-axSpA, $\%$ & - & - & - & 51 & 50 & 53 \\
\hline
\end{tabular}

Conclusions: In clinical practice, the frequency of women initiating BT have not increased since its approval for $\mathrm{nr}-\mathrm{axSpA}$. Additionally, women treated nowadays with BT have more objective parameters of disease activity than they used to do. This supports that when treating axSpA women (including nr-axSpA) with $\mathrm{BT}$, we are currently treating axSpA -and not fibromyalgia- patients.

Disclosure of Interest: None declared

DOI: 10.1136/annrheumdis-2018-eular.4190

\begin{tabular}{|l}
\hline OP0323 \\
ARE GENDER-SPECIFIC APPROACHES NEEDED IN \\
DIAGNOSING EARLY AXIAL SPONDYLOARTHRITIS? \\
DATA FROM THE SPONDYLOARTHRITIS CAUGHT \\
EARLY COHORT
\end{tabular}

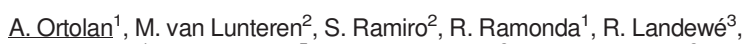
H. Dagfinrud ${ }^{4}$, L. Jacobsson ${ }^{5}$, D. van der Heijde ${ }^{2}$, F.A. van Gaalen².

${ }^{1}$ Rheumatology Unit, Department of Medicine DIMED, University of Padova, Padova, Italy; ${ }^{2}$ Department of Rheumatology, Leiden University Medical Center, Leiden; ${ }^{3}$ Department of Rheumatology, Amsterdam Rheumatology and Immunology Center, Amsterdam, Netherlands; ${ }^{4}$ Department of Rheumatology, Diakonhjemmet Hospital, Oslo, Nonway; ${ }^{5}$ Department of Rheumatology, University of Gothenburg, Gothenburg, Sweden

Background: Although gender differences have been observed in the severity of axial spondyloarthritis (axSpA), gender differences in disease presentation of early axSpA have not been thoroughly investigated.

Objectives: Our aim was to assess if the disease presents differently in males and females, and to evaluate if this has an impact on the diagnostic process.

Methods: Baseline data from the SPondyloArthritis Caught Early cohort, which includes patients with chronic back pain (CBP; $\geq 3$ months, $\leq 2$ years, onset $<45$ years), were analysed. Patients underwent a full diagnostic workup, including MRI and radiograph of the sacroiliac joints (MRI-SIJ and X-SIJ), to establish a diagnosis of axSpA. Characteristics of male and female patients with a definite diagnosis of axSpA (based on a level of confidence about the diagnosis $\geq 7$, as expressed by the physician on a $0-10$ rating scale) were compared. Regression models were built for 1) the whole CBP cohort stratified by gender to study which SpA features were associated most with diagnosis in each gender, and 2) for axSpA patients to test if gender was associated with imaging positivity (MRI SIJ+and/or $\mathrm{X}-\mathrm{SIJ}+$ ).

Results: Of the 719 CBP patients, 275 were male. With 146/275 (53.1\%) males and $155 / 444$ (34.9\%) females diagnosed as axSpA, males were more likely to be diagnosed with axSpA (OR 2.1,95\% Cl: 1.5 to 2.9). Despite similar symptom duration, male axSpA patients were younger at diagnosis (27.4 \pm 7.5 vs $29.5 \pm 7.8$ years; $p=0.021$ ). Presence of $S p A$ features was similar in male and female axSpA patients (table 1) except for HLA-B27 and imaging positivity, which were more common in male axSpA patients (HLA-B27 $+80 \%$ vs $60 \%$; $p<0.0001$ and positive imaging $78 \%$ vs $64 \% ; p=0.007$ ). Nevertheless, both these $\mathrm{SpA}$ features were still more prevalent in female axSpA patients than in non-axSpA patients, either females (HLA-B27 $+23 \%$ and imaging $7 \%$ ) or males (HLA-B27 $+34 \%$ and positive imaging $11 \%$ ) (all $\mathrm{p}<0.001)$. Moreover, in multivariable models with diagnosis as 